The author includes 26 graphs taken from the 97 cases on which his monograph is based to show the progress of the treatment; in 21 of these 26 cases, surgical adjustments were necessary to shorten or lengthen the capsule of Tenon, but Mr. Stutterheim is generally opposed to any other form of operation. It is interesting to note that among the cases illustrated are three with paralysed muscles and ten with alternating squints.

The author outlines a plan, primarily for South Africa but capable, no doubt, of being adapted to the requirements of other countries, which is designed to ensure that no child leaves his primary school with a squint. The plan is based on the establishment of special well-equipped clinics each run by a physiologist and two capable nurses who would be able to cure 40 squinters a year; these clinics would form an integral part of the educational scheme and in this connection the author stresses the importance of removing squinting children from their home surroundings during treatment.

$\mathrm{Mr}$. Stutterheim claims that the treatment of squints should be placed in the hands of medically qualified physiologists: in making this claim, he says (p. 30) "it should certainly in no wise be left in the hands of surgeons and optometrists. And it would be most disastrous if it were left to amateur or techically trained lay people, "orthoptic 3" or otherwise". It is unfortunate that in his enthusiasm the author allows himself more than once to make sweeping comments of this type without justification. From the orthoptic point of view, he appears to ignore entirely the important and substantial progress of recent years and it would require more space than is available in a bxief review to give a full critical assessment of his treatment.

Nevertheless Mr. Stutterheim's monograph opens a new line of thought which deserves serious consideration and it would be a pity if his intolerance of other methods were allowed to detract from the value of the research which he has carried out.

\title{
CORRESPONDENCE
}

\section{LOCALISATION OF INTRA-OCULAR FOREIGN BODIES}

To the Editors of THE BRITISH Journal of OpHTHALMology.

DEAR SIRS,-With reference to the recent letter of Mr. Bernard Gluck on the localisation of intra-ocular foreign bodies I enclose a photograph of two instruments which I have found of considerable practical use. 
The-spectacle frame, with cross wires, movable cursor and synthetic non-opaque arms (Love's method of localisation) was discarded as soon as I learnt of the limbal ring method in the first of $\mathrm{Mr}$. H. B. Stallard's papers on this subject. I found Love's method useful, however, in gauging the site of extra-ocular foreign bodies in the region of the eye. The spectacle frame was held firmly on the face by elastic attached to the arms.

Fl. Lt. C. M. Brown of the Royal Air Force Dental Service, very kindly made for me contact glasses of portex in which the opaque limbal ring was embedded as near the inner' surface as possible. These were used in the same way as stitched-on rings. type.

Two practical points arose in using contact glass localisers of this

(1) An embedded opaque ring appeared to be the best form for measuring off the situation of the eye on the X-Ray film.

(2) It was a great advantage to have a small square projection on the middle of the anterior surface of the contact glass in order

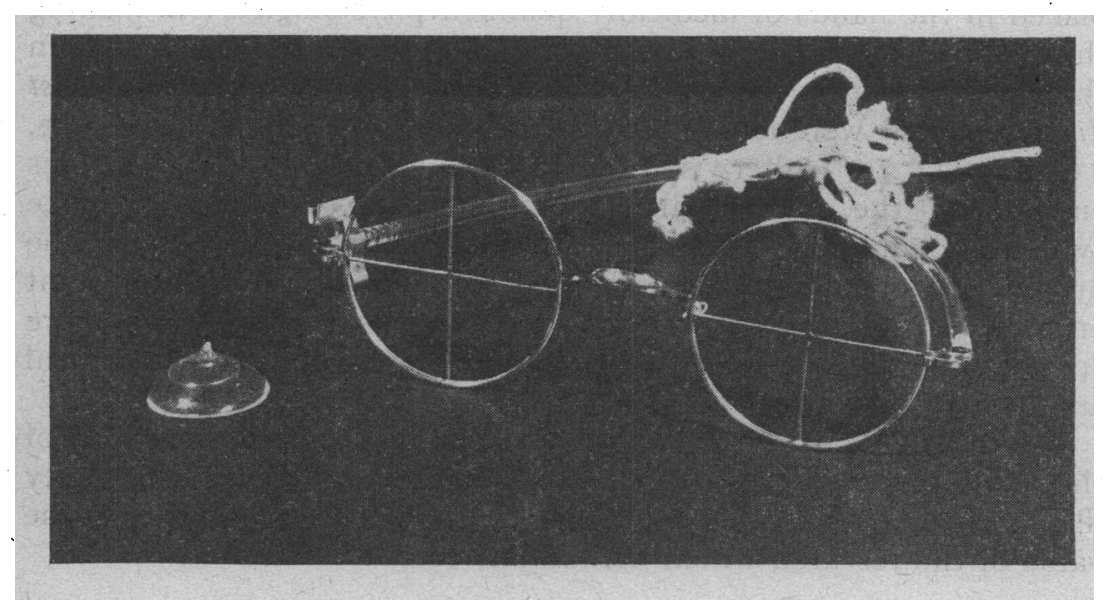

that the ring could be pushed into exact position on the limbus immediately before each X-Ray was taken. The slight increase of shadow in the A.P. picture at the site of the projection was not found to be a disadvantage in practice.

I am indebted to Fl. Lt. B. C. Elliott for the photograph and to Air Commodore P. C. Livingston, C.B.E. for permission to describe these instruments.

Yours faithfully,

F. W. G. Sмiтh.

CaMPden LODge,

Westgate-on-Sea.

July 12, 1946. 